\title{
Polimorfismos em Anopheles (Kerteszia) cruzii Dyar \& Knab (Diptera, Culicidae) detectados através de PCR-RAPD. Variabilidade genética entre indivíduos de mesma progênie ${ }^{1}$
}

\author{
Daniéla C. Calado ${ }^{2} \&$ Mario A. Navarro-Silva ${ }^{2}$ \\ ${ }^{1}$ Contribuição número 1585 do Departamento de Zoologia, Universidade Federal do Paraná. \\ ${ }^{2}$ Laboratório de Entomologia Médica e Veterinária, Departamento de Zoologia, Universidade Federal do Paraná. Caixa \\ Postal 19020,81531-980 Curitiba, Paraná, Brasil.E-mail: danielacalado@hotmail.com, mnavarro@ufpr.br
}

\begin{abstract}
Polimorphisms in Anopheles (Kerteszia) cruzii Dyar \& Knab (Diptera, Culicidae) detected by PCRRAPD. Genetic variability in individuals from same progeny. Genetic variation in broods of Anopheles cruzii was studied. Mosquitoes were collected in Morretes and Paranaguá (two municipalities in the State of Paraná, Southern Brazil) from which broods were reared. DNA was collected from these broods, from which six randomsequence primers were used in PCR. In within-brood analyses, all markers revealed a high-degree of polymorphisms within the broods. Detailed studies of the within-brood variability will help solve taxonomic problems in this group, since differences in fragment patterns are used to distinguish species.
\end{abstract}

KEY WORDS. Anopheles bellator, malaria vector, random amplified polymorphic DNA.

RESUMO. A variabilidade genética entre indivíduos de Anopheles cruzii procedentes de mesma progênie foi estudada. As progênies foram obtidas a partir de mosquitos coletados em Morretes e Paranaguá (dois municípios do estado do Paraná, região sul do Brasil). DNA foi extraído de cada indivíduo das diferentes progênies e seis iniciadores foram utilizados na PCR. Nas análises, todos os iniciadores revelaram alto grau de polimorfismos. $\mathrm{O}$ estudo detalhado da variabilidade existente entre indivíduos de mesma progênie poderá auxiliar a resolver problemas taxonômicos nesse grupo, tendo em vista que diferentes padrões de fragmentos são utilizados para identificar espécies.

PALAVRAS CHAVE. Anopheles bellator, DNA polimórfico amplificado ao acaso, variabilidade genética, vetor.

A utilização de caracteres moleculares para caracterização de uma espécie, ou de suas populações, deve levar em consideração a diversidade genética existentes entre diferentes níveis (ex. individual, populacional e específico). Entretanto, a maioria dos estudos realizados com anofelíneos (Culicidae, Anophelinae) tem despendido pouca atenção ao estudo da variabilidade genética individual, e menos ainda à diversidade entre indivíduos irmãos, o que pode gerar problemas no momento da determinação de caracteres a serem utilizados em estudo taxonômicos ou ecológicos.

A análise de populações naturais através de determinados marcadores moleculares, por exemplo RAPD, pode revelar grande número de polimorfismos, que nem sempre apresentam significado taxonômico. Em alguns casos, a determinação de quais bandas são realmente informativas torna-se ainda mais difícil quando há suspeita de existência de espécies crípticas. Desta forma, a análise de indivíduos que certamente pertencem a um mesmo táxon (ex. indivíduos irmãos) pode auxiliar no entendimento do grau de diversidade genética do grupo e na escolha dos caracteres mais informativos ao problema proposto.

Dentre as espécies de anofelíneos neotropicais, Anopheles (Kerteszia) cruzii Dyar \& Knab, 1908 destaca-se por ser considerado vetor potencial de Plasmodium Marchiafava \& Celli, 1885 nos litorais sul e sudeste do Brasil. Aquela espécie apresenta considerável número de polimorfismos genéticos, revelados por análises citogenéticas (RAMIREZ \& DESSEN 2000a,b), isoenzimáticas (CARvalho-Pinto \& Lourenço-De-Oliveira 2004) e moleculares (Mallafronte et al. 1997), podendo constituir um complexo de espécies. Porém, essas análises têm sido realizadas ao nível populacional e nenhuma tem abordado a variabilidade entre indivíduos de mesma geração filial, o que poderia auxiliar no entendimento do significado taxonômico dos polimorfismos observados na espécie. Por isso, este trabalho teve como objetivo analisar a variabilidade genética entre indivíduos de Anopheles (K.) cruzii pertencentes à mesma progênie, a fim de obter informações que possam ser utilizadas em estudos que utilizem marcadores RAPD para caracterização de populações desse táxon. 

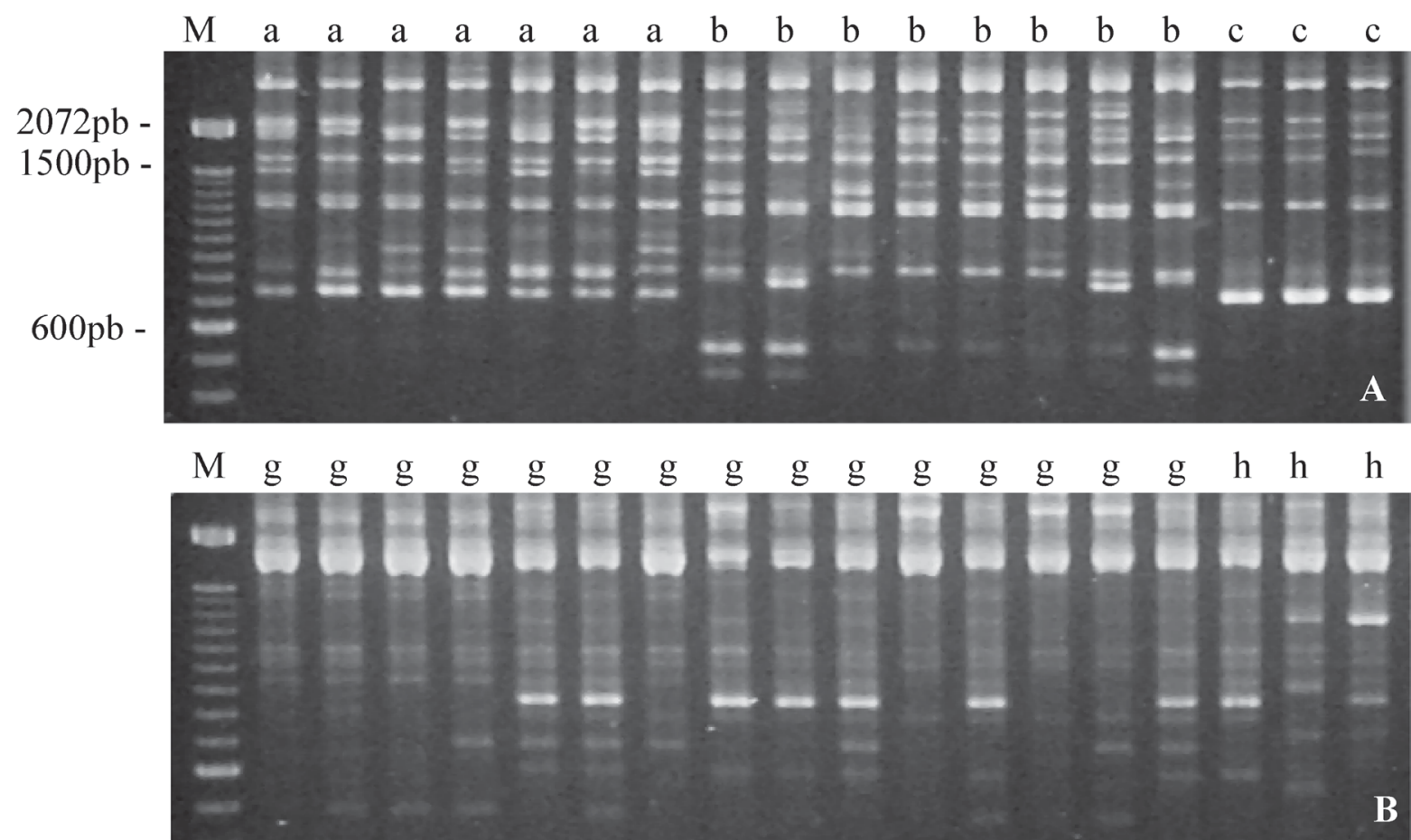

Figura 1. Comparação entre os fragmentos amplificados através de PCR-RAPD, em indivíduos de mesma progênie, obtidos com o iniciador OPY-15. Anopheles cruzii (a, b, c) e Anopheles bellator (g, k). (M) marcador 100pb DNA Ladder (Invitrogen). Letras iguais indicam indivíduos irmãos.

\section{MATERIAL E MÉTODOS}

\section{Método de coleta e amostras analisadas}

A análise da variabilidade genética entre indivíduos de Anopheles (K.) cruzii pertencentes à mesma progênie foi realizada a partir da geração F1 de fêmeas capturadas em campo. As capturas de anofelíneos adultos foram realizadas em área de Floresta Atlântica do litoral paranaense, nas localidades de Morretes $\left(48^{\circ} 49^{\prime} \mathrm{W}, 25^{\circ} 30^{\prime} \mathrm{S}\right)$ e Ilha do Mel (Paranaguá) (48 $\left.18^{\prime} 44.7^{\prime \prime} \mathrm{W}, 25^{\circ} 30^{\prime} 36.0^{\prime \prime} \mathrm{S}\right)$, utilizando a técnica de pousohomem. Em laboratório, as fêmeas capturadas foram individualizadas para obtenção de posturas e posterior identificação. O número de descendentes analisados foi diferente para cada fêmea, tendo em vista a dificuldade de manutenção e obtenção de posturas em laboratório. Para efeito de comparação, amostras de Anopheles (Kerteszia) bellator Dyar \& Knab, 1906 também foram analisadas. A comparação entre amostras de Anopheles (K.) cruzii foi realizada a partir de 41 indivíduos pertencentes a seis progênies diferentes (denominadas A-F) e para Anopheles (K.) bellator 36 indivíduos de seis progênies (denominadas G-L) foram analisados.

\section{Extração de DNA e PCR-RAPD}

A extração de DNA foi realizada segundo protocolo de Cheung et al. (1993) modificado por Carvalho \& Vieira (2001).
A reação de amplificação foi conduzida em volume total de $25 \mu \mathrm{l}$, contendo 15-30ng de DNA, 1X PCR buffer, $3 \mathrm{mM}$ de $\mathrm{MgCl}_{2}, 100 \mu \mathrm{M}$ de cada dNTP, 5 pmol de iniciador (Operon Technologies Inc. Alameda, CA.), 1 U de Taq DNA polimerase (Invitrogen) e água Milli-Q estéril para completar o volume final. A PCR foi realizada em termociclador PTC-100 ${ }^{\mathrm{TM}}$ (MJ Research, Inc. Watertown, MA), utilizando-se os seguintes ciclos de temperatura: desnaturação inicial a $94^{\circ} \mathrm{C}$ por três minutos, 41 ciclos de desnaturação a $94^{\circ} \mathrm{C}$ por um minuto, anelamento a $35^{\circ} \mathrm{C}$ por um minuto e extensão a $72^{\circ} \mathrm{C}$ por dois minutos, e extensão final a $72^{\circ} \mathrm{C}$ por quatro minutos. Cada reação foi repetida uma a duas vezes para confirmação da posição e reprodutibilidade das bandas. Controles negativos foram incluídos. Seis iniciadores, OPA-11, OPY-02, OPY-05, OPY-15 e OPY-16, foram utilizados para comparação entre os diferentes indivíduos.

\section{Eletroforese}

Os produtos de PCR foram fracionados em gel de agarose $1,5 \%$ contendo $0,5 \mathrm{X} \mathrm{TBE}$, a $5 \mathrm{~V} / \mathrm{cm}$ durante três horas e corados com solução de brometo de etídio $(0,5-1 \mu \mathrm{g} / \mathrm{ml})$ por $20-30$ minutos. Como marcador de peso molecular foi utilizado $100 \mathrm{pb}$ DNA Ladder (Invitrogen). A captura das imagens (sob luz ultravioleta) e o cálculo do peso molecular aproximado das bandas foram realizados com auxílio do sistema Kodak Digital Science EDAS 120.

Revista Brasileira de Zoologia 22 (4): 1121-1126, dezembro 2005 

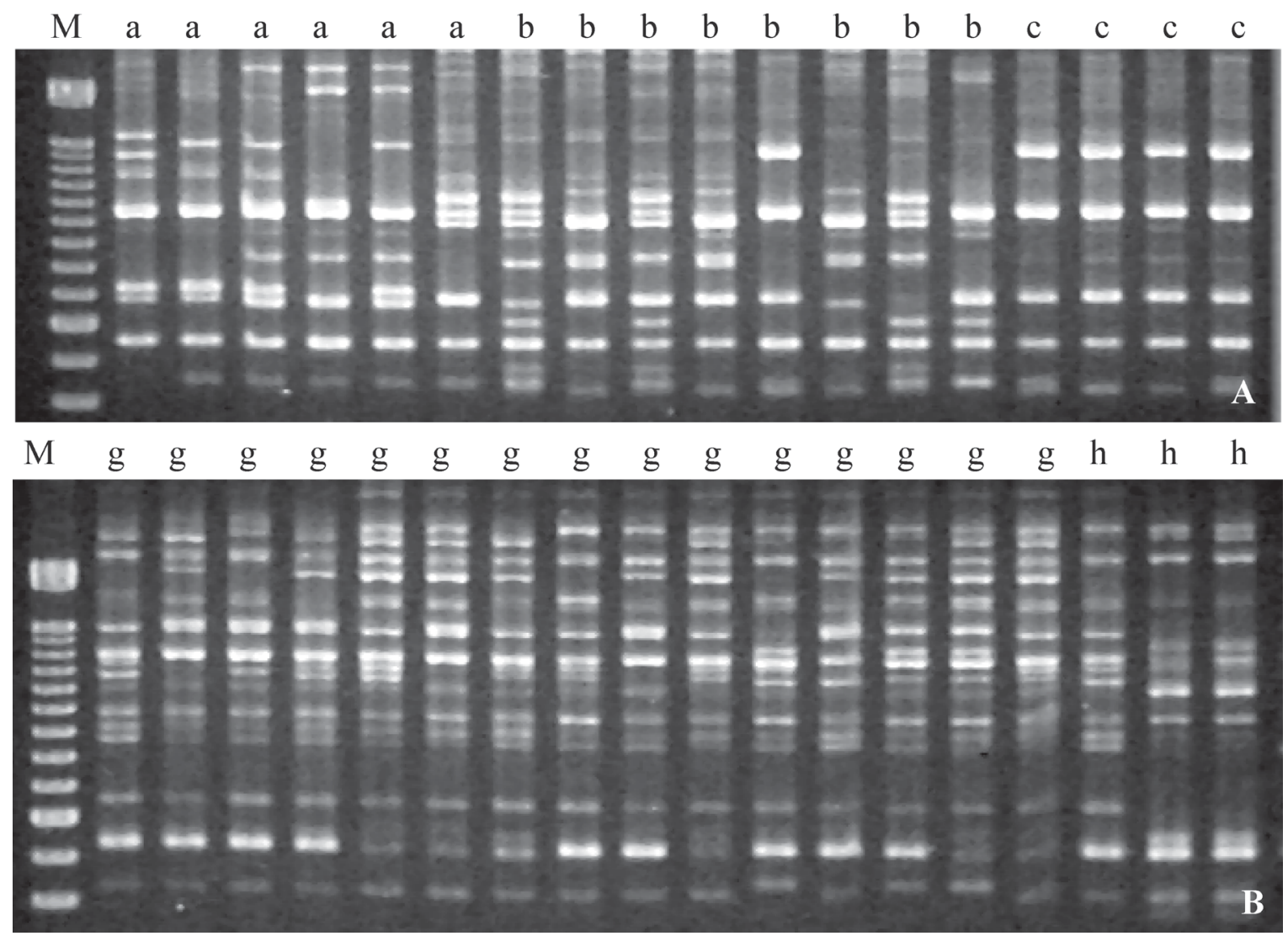

Figura 2. Comparação entre os fragmentos amplificados através de PCR-RAPD, em indivíduos de mesma progênie, obtidos com o iniciador OPY-10. Anopheles cruzii ( $\mathrm{a}, \mathrm{b}, \mathrm{c})$ e Anopheles bellator (g, k). (M) marcador 100pb DNA Ladder (Invitrogen). Letras iguais indicam indivíduos irmãos.

\section{RESULTADOS E DISCUSSÃO}

Os perfis obtidos através da amplificação do DNA de Anopheles (K.) cruzii e Anopheles (K.) bellator com os iniciadores OPA-11, OPY-02, OPY-05, OPY-10, OPY-15 e OPY-16 revelaram grande número de fragmentos polimórficos, indicando considerável variabilidade genética entre indivíduos irmãos, a qual é variável de acordo com o iniciador utilizado. Nas figuras 1 a 4, são apresentados os perfis obtidos com os iniciadores OPY15, OPY-10, OPY-16 e OPA-11, nas diferentes progênies das duas espécies analisadas.

A sensibilidade da PCR-RAPD na detecção de polimorfismos é grande, sendo possível a identificação de genótipos e obtenção de "fingerprints" genômicos. Desta forma, os polimorfismos observados podem ser resultantes de pequenas alterações na seqüência de DNA de diferentes indivíduos, decorrentes de mudanças na seqüência do sítio de iniciação (inserções/ deleções/substituições) ou de alterações que modifiquem o tamanho da seqüência a ser amplificada (inserções/deleções). Diferenças em apenas um par de bases podem ser detectadas pela técnica (Williams et al. 1990) e por isso, grande número de polimorfismos pode ser revelado em indivíduos proximamente relacionados, inclusive irmãos.

Dentre os fragmentos obtidos em Anopheles (K.) cruzii, alguns foram observados em todas as progênies, enquanto outros se mostraram exclusivos à determinada família ou a um conjunto de indivíduos dentro da progênie. Por exemplo, os fragmentos de aproximadamente 2550pb, 2250pb, 1350pb e 880pb (OPY05), 550pb (OPY-10), 1120pb e 1150pb (OPY-02), 1300pb (OPA11) e $2500 \mathrm{pb}$ (OPY-15) foram amplificados em todas as progênies, enquanto a banda de aproximadamente 650pb amplificada com o iniciador OPY-10 foi observada somente em alguns indivíduos da progênie B. Em Anopheles (K.) bellator, também foram observadas diferenças quanto ao padrão de bandas geradas entre indivíduos irmãos e entre progênies, e todos os iniciadores foram capazes de revelar polimorfismos. As bandas de 2300pb, $2000 \mathrm{pb}$ e $1200 \mathrm{pb}$ (OPY-02), 1000pb (OPY-10), 1700pb (OPA-11) e $470 \mathrm{pb}$ e $570 \mathrm{pb}$ (OPY-16) foram observadas em todas as famílias analisadas, enquanto as demais foram polimórficas entre indivíduos irmãos e/ou entre as progênies.

Revista Brasileira de Zoologia 22 (4): 1121-1126, dezembro 2005 

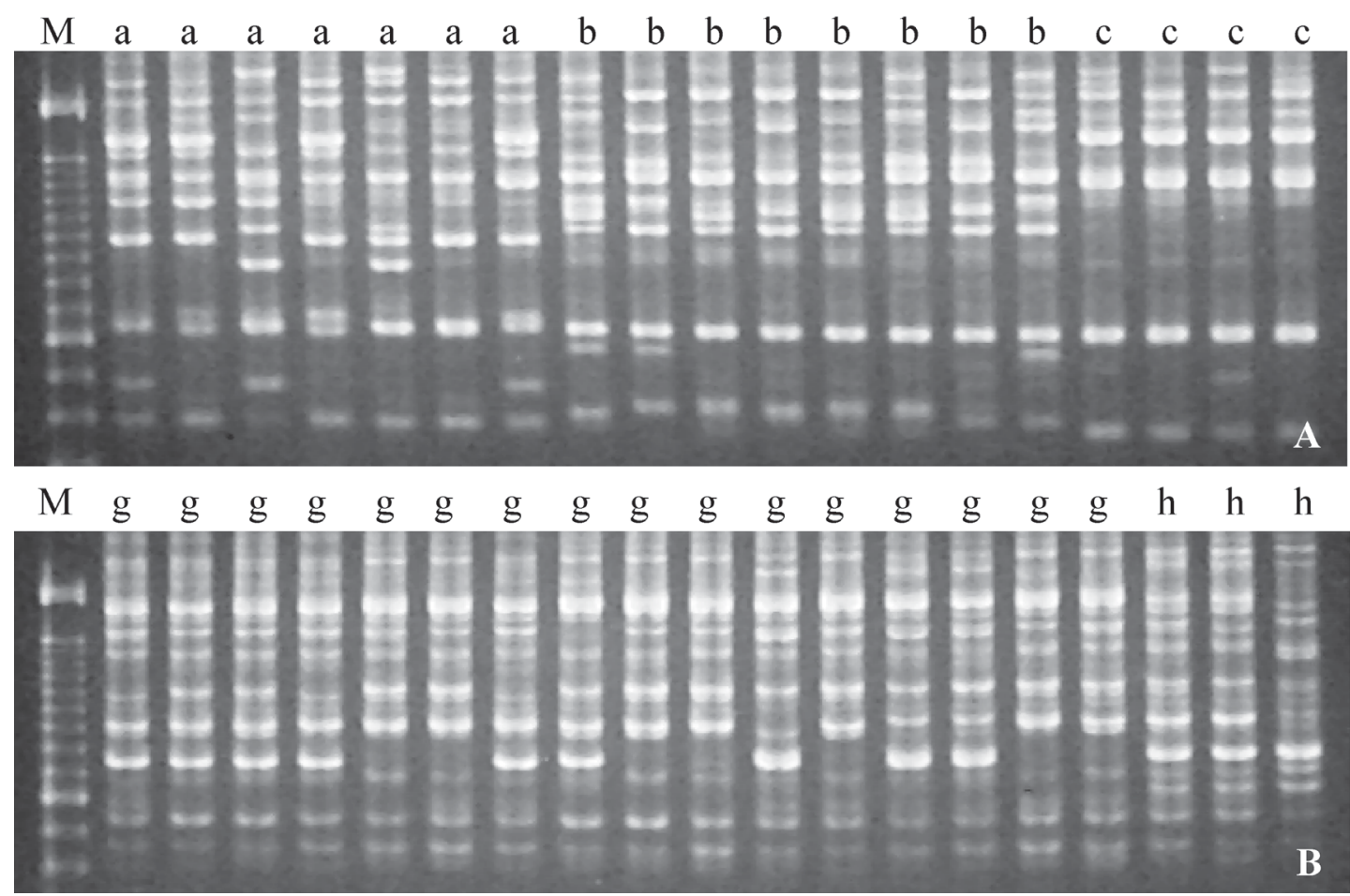

Figura 3. Comparação entre os fragmentos amplificados através de PCR-RAPD, em indivíduos de mesma progênie, obtidos com o iniciador OPY-16. Anopheles cruzii ( $a, b, c)$ e Anopheles bellator (g, k). (M) marcador 100pb DNA Ladder (Invitrogen). Letras iguais indicam indivíduos irmãos.

Em Culicidae, poucos trabalhos têm analisado a variabilidade genética entre indivíduos irmãos e, portanto, torna-se difícil a comparação com os resultados aqui obtidos. Entretanto, os polimorfismos observados entre indivíduos de mesma geração filial podem estar associados ao tipo de reprodução exibido pelas espécies, tendo em vista que a reprodução sexuada constitui-se num dos principais mecanismos responsáveis pela amplificação da variação genética. Em organismos com esse tipo de reprodução, o número de polimorfismos detectados pela PCR-RAPD é grande e os loci considerados polimórficos podem estar presentes em um ou ambos parentais (BALLINGER-CABTREE et al. 1992). No presente trabalho, apenas fêmeas foram coletadas e como não foi possível a manutenção de espécies de Anopheles (Kerteszia) em laboratório, não foi permitido verificar a segregação das bandas de parentais para descendentes e nem o padrão de herança. Porém, algumas bandas RAPD podem segregar como marcadores mendelianos (FAVIA et al. 1994, TAVAres et al. 2001). FAviA et al. (1994) verificaram que quando uma fêmea de Anopheles (Cellia) gambiae Gilles, 1902 heterozigota para um dado locus RAPD era cruzada com um macho que não apresentava determinado fragmento, a presença dessa banda era observada em parte da progênie, 8 em 18 .

Outra possibilidade para explicar o número de fragmentos polimórficos entre indivíduos irmãos nas espécies analisa- das, envolve a cópula com mais de um macho. Embora em Aedes (Stegomyia) aegypti, as fêmeas tornem-se refratárias a subsequentes cópulas devido à ação de substâncias produzidas pelas glândulas acessórias do macho, em Anopheles existem evidências de que podem ocorrer múltiplas cópulas (KLOWDen 2001). Em Anopheles (C.) gambiae, por exemplo, o macho produz uma massa gelatinosa que forma um tampão de cópula para impedir a fertilização da fêmea por outros indivíduos. Entretanto, esta proteção não é efetiva e o tampão pode ser dissolvido em menos de 24 horas (ForATTINI 2002), permitindo que a fêmea possa ser fecundada mais de uma vez. Como os exemplares analisados são originários de fêmeas fecundadas em campo, não há garantia de que todos os indivíduos produzidos por uma mesma fêmea sejam resultantes da cópula exclusiva com um macho.

Apesar do grande número de bandas geradas pela PCRRAPD, poucas podem constituir caracteres informativos para estudos taxonômicos ou para caracterização de diferentes populações dessa espécie, pois mostraram-se altamente polimórficas entre indivíduos irmãos. Desta forma, o estudo da variabilidade em progênies permite o melhor reconhecimento de fragmentos variáveis dentro da espécie, e que poderiam ser erroneamente utilizados como caracteres taxonômicos para identificação de espécies semelhantes ou indistinguíveis morfologicamente (crípticas), especialmente quando poucas amostras são

Revista Brasileira de Zoologia 22 (4): 1121-1126, dezembro 2005 

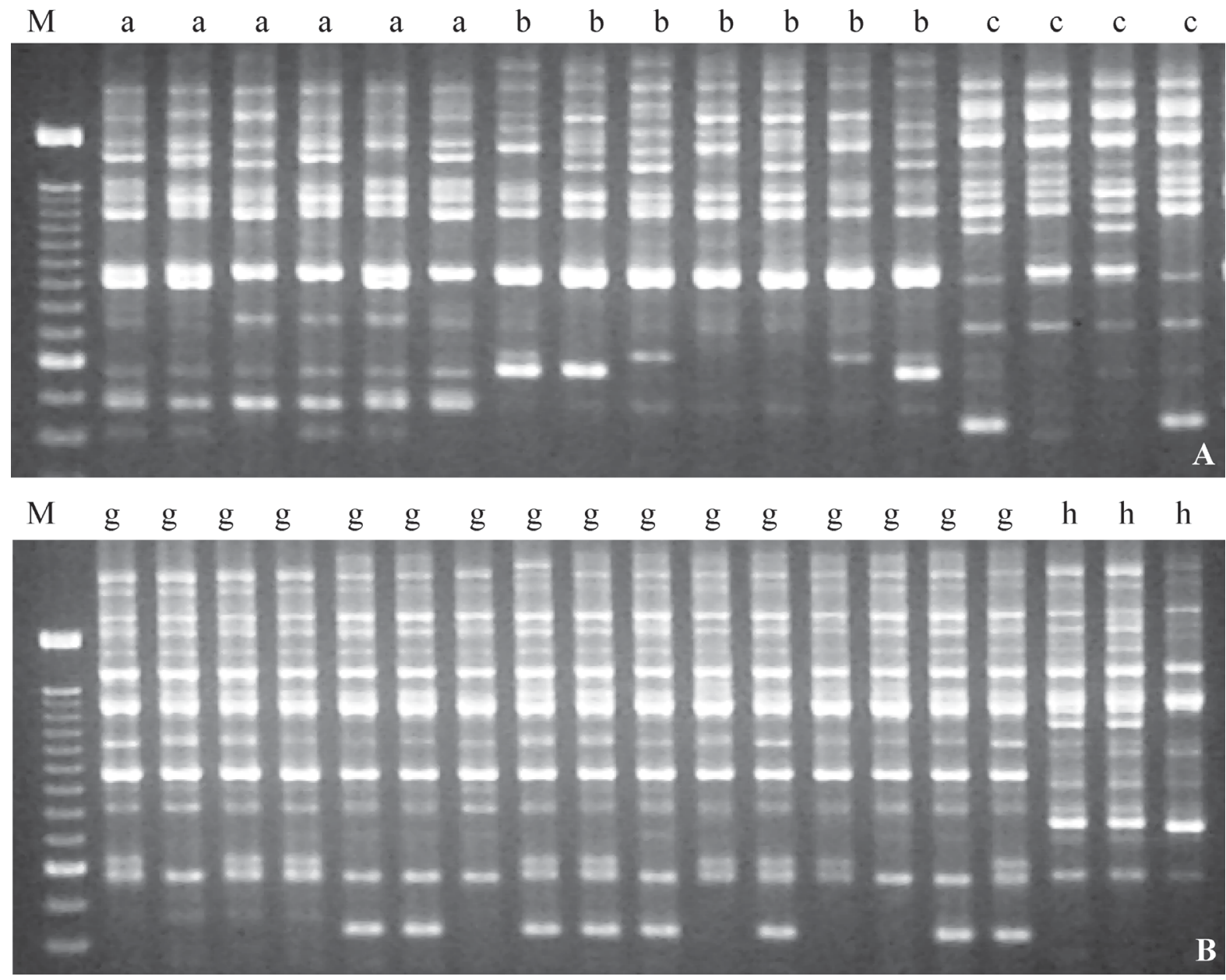

Figura 4. Comparação entre os fragmentos amplificados através de PCR-RAPD, em indivíduos de mesma progênie, obtidos com o iniciador OPA-11. Anopheles cruzii ( $\mathrm{a}, \mathrm{b}, \mathrm{c})$ e Anopheles bellator (g, k). (M) marcador 100pb DNA Ladder (Invitrogen). Letras iguais indicam indivíduos irmãos.

analisadas. Além disso, a análise de indivíduos irmãos permite o melhor entendimento da variabilidade dentro e entre diferentes populações, ou seja, se certa heterogeneidade quanto aos fragmentos RAPD amplificados é observada entre indivíduos de mesma geração filial, conseqüentemente, grande variabilidade genética entre indivíduos de uma população local ou de localidades diferentes também é esperada. A utilização de PCR-RAPD em diferentes populações de Anopheles (K.) cruzii deverá revelar considerável diversidade genética, com poucas bandas sendo constantes em todas as amostras analisadas.

\section{AGRADECIMENTOS}

Ao pesquisador Dr. Luiz Gonzaga Esteves Vieira do Laboratório de Biotecnologia Vegetal do Instituto Agronômico do Paraná pelo apoio técnico e cessão do laboratório para realização das análises com marcadores moleculares, e ao CNPq pelas bol- sas de Doutorado (D.C.C. - Processo: 140698/2001-9) e de produtividade em pesquisa (M.A.N.S. - Processo: 302350/2003-9).

\section{REFERÊNCIAS BIBLIOGRÁFICAS}

Ballinger-Crabtree, M.E.; W.C. Black IV \& B.R. Miller. 1992. Use of genetic polymorphisms detected by the Randon amplified polymorphic DNA polymerase chain reaction (RAPD-PCR) for differentiation and identification of Aedes aegypti subspecies and populations. American Journal of Tropical Medicine and Hygiene, Cleveland, 47 (6): 893-901.

Carvalho, A.O. \& L.G.E. Vieira. 2001. Determinação das condições ótimas para análise de PCR-RAPD em Atta sexdens rubropilosa Forel (Hymenoptera: Formicidae). Neotropical Entomology, Londrina, 30 (4): 593-600.

Carvalho-Pinto, C.J. \& R. Lourenço-de-Oliveira. 2004. Isoenzimatic analysis of four Anopheles (Kerteszia) cruzii (Diptera:

Revista Brasileira de Zoologia 22 (4): 1121-1126, dezembro 2005 
Culicidae) populations of Brazil. Memórias do Instituto Oswaldo Cruz, Rio de Janeiro, 99 (5): 471-475.

Cheung, W.Y.; N. Hubert \& B.S. LANDry. 1993. A simple and rapid DNA microextraction method for plant, animal and insect suitable for RAPD and other PCR analyses. PCR Methods and Applications, New York, 3: 69-70.

Favia, G.; G. Dimopoulos \& C. Louis. 1994. Analysis of the Anopheles gambiae genome with RAPD markers. Insect Molecular Biology, Oxford, 3 (3): 149-157.

ForattinI, O.P. 2002. Culicidologia Médica. São Paulo, Editora da Universidade de São Paulo, 860p.

KLowden, M.J. 2001. Sexual receptivity in Anopheles gambiae mosquitoes: absence of control by male acessory gland substances. Journal of Insect Physiology, Oxford, 47: 661666.

Mallafronte, R.S.; M.T. Marrelli; G.C. Carreri-Bruno; P.R. Urbinatti \& O. MarinotTi. 1997. Polymorphism in the second internal spacer (ITS2) of Anopheles (Kerteszia) cruzii (Diptera: Culicidae) from the State of São Paulo, Brazil. Memórias do Instituto Oswaldo Cruz, Rio de Janeiro, 92 (Supl. I): 306.

Ramirez, C.C.L. \& E.M.B. Dessen. 2000a. Chromosomal evidence for sibling species of the malaria vector Anopheles cruzii. Genome, Otawa, 43: 143-151.

Ramirez, C.C.L. \& E.M.B. Dessen. 2000b. Chromosome differentiated populations of Anopheles cruzii: evidence for a third sibling species. Genetica, Dordrecht, 108: 73-80.

Tavares, M.G.; E.H. Ribeiro; L.A.O. Campos; E.G. Barros \& M.T.V.A. OliverrA. 2001. Inheritance patterns of RAPD markers in Melipona quadrifasciata (Hymenoptera: Apidae, Meliponinae). Journal of Heredity, Oxford, 92 (3): 279-282.

Williams, J.G.K.; A.R. Kubelik; K.J. Livak \& J.A. Rafalski. 1990. DNA polymorphisms amplified by arbytrary primers are useful as genetic markers. Nucleic Acids Research, Oxford, 18: 6531-6535.

Recebido em 07.IV.2005; aceito em 14.XI.2005. 